\title{
In Vitro Antioxidant Activity of Chufa Tubers (Cyperus esculentus L.) Extracts in Liposome Peroxidation Systems
}

\author{
M. Zommara* and K. Imaizumi** \\ *Department of Dairy Science, Faculty of Agriculture, Kafrelsheikh University, Kafr \\ El-sheikh 33516, Egypt and ${ }^{* *}$ Graduate School of Bioresource and Bioenvironmental \\ Sciences, Department of Bioscience and Biotechnology, Kyushu University, Fukuoka, \\ 6-10-1 Hakozaki, Higashi-ku 812-8581, Japan
}

\begin{abstract}
$\mathbf{T}$ HE ANTIOXIDANT activity of hexane, ethanol or water extracts of chufa tubers (Cyperus esculentus $\mathrm{L}$.) were investigated in vitro using liposome peroxidation systems. Incorporation of $1 \mathrm{mg} / \mathrm{ml}$ of chufa oil, water or ethanol extracts of the tubers to phosphatidylcholine (PtdCho) liposomes displayed different antioxidative activity. All fractions possessed antiperoxidation activity in ferrous ions dependent peroxidation stress and in free radical mediated peroxidation by the water soluble initiator 2,2'-azobis (2-aminopropane) dihydrochloride (AAPH), while the water extract possessed the strongest effect. However, in the lipid soluble free radicals initiator 2,2'-azobis (2,4-dimethylvaleronitrile) (AMVN) mediated peroxidation, the antioxidant activity was found only by the oil fraction. The antioxidant activity of chufa oil may be attributed to its fatty acid profile and vitamin E content. Chufa oil contains about $72 \%$ of monounsaturated fatty acids, mainly oleic acid and $18.6 \mathrm{mg} / 100 \mathrm{~g}$ of vitamin $\mathrm{E}$. The resistance of chufa water and ethanol extracts may be attributed in part to its isoflavones content $(20.9 \mu \mathrm{g} / \mathrm{g})$.
\end{abstract}

Keywords: Chufa, olive oil, Anhydrous milk fat, Liposome, Antioxidant activity, Lipoperoxidation, Ferrous ions, AAPH, AMVN

\section{Introduction}

Chufa plant is a member of the grass family Cyperaceae to which nutsedge weeds also belong. Chufa tubers are daily ingredients of the diet of many people in North Africa and Spain. In North Africa the tubers are consumed in their natural form or after being soaked in water for some hours. In Spain, the tubers are consumed mainly as a drink called locally "horchata de chufa" (chufa milk). The use of chufa tubers in Egypt is limited to be eaten as a nut on certain occasions or as a coffee adulterant. The tubers of this plant are known by several names, such as tiger nut, earth nut, earth almond, rush nut and chufa. Several studies demonstrated the high nutritional quality of chufa tubers (Arafat et al., 2009, Adejuyitan 2011 and Codina-Torrella et al., 2015). It provides about $400-450 \mathrm{kcal} / 100 \mathrm{~g}$ tubers due to its high oil content $(\sim 25 \%)$ and carbohydrates $(\sim 50 \%)$. It also contains considerable amounts of protein $(\sim 8 \%)$, dietary fibers $(\sim 6 \%)$, minerals $(\sim 4 \%)$ i.e. calcium, sodium, potassium, magnesium and phosphorus and several enzymes in particular, catalase, lipase and amylase (Adejuyitan, 2011). According to its nutritional value, chufa tubers are considered as an interesting solution for the protein-calorie malnutrition in the developed countries, and a promising material for the production of gluten free bread for people with celiac disease (Aguilar et al., 2015). Chufa can be eaten raw, baked, roasted or processed into drink. It can also be used as a flavoring agent for ice cream and biscuits (Cantatejo, 1997).

Dietary nutrients with antioxidant properties are of great significance in the pathogenesis of many disorders related to free radical damage (Mancini et al., 1995, Owen et al., 2000 and Dipartimento, 2000). Therefore, the research regarding the use of the antioxidant rich ingredients in food production take a special interest. Chufa oil contains about $70 \%$ of oleic acid. Oleic acid was reported to have a protective 
effect against peroxidation stress either in vitro when incorporated to liposomes (Lee et al., 1998) or in vivo when supplied to a diet (Bonanome et al., 1992 and Sola et al., 1997). In a preliminary note, Mohamed and El-Fors (1959) have reported that a small amount of chufa oil $(6 \%)$ protected linseed oil against peroxidation stress in in vitro. The aim of the present study is to explore the antioxidant activity of extracts of chufa tubers by hexane (oil fraction), ethanol or water in transition metal ions-dependent peroxidation or in free radicals mediated peroxidation stress by the aqueous- or lipids-phase, azo-derived peroxyl radicals AAPH and AMVN,respectively when incorporated to multi-lamellar liposomes.

\section{Materials and Methods}

Chufa tubers were purchased from the local market at Kafr El-Sheikh city, Egypt. The tubers were sorted for stone and other physical defects, washed and dried overnight at $60^{\circ} \mathrm{C}$ as described by Amankwah et al. (2009). The tubers were allowed to cool, and then milled using a laboratory miller to pass through 40 mesh sieve.

\section{Chemical composition of chufa tubers}

Chemical composition of chufa tubers was determined according to the methods described by the AOAC (1995).

\section{Analysis of fatty acid composition}

Fatty acid composition of chufa oil, olive oil and anhydrous cow milk fat was determined using GLC as described by Imaizumi et al. (1993).

\section{Determination of vitamin $E$ content}

The concentration of vitamin $\mathrm{E}$ in chufa oil was determined by high-performance liquid chromatography (HPLC) (Waters 600E, Japan Millipore, Tokyo) according to the method described by Zommara et al. (1998).

\section{Determination of isoflavones}

Chufa isoflavones were extracted with $70 \%$ aqueous ethanol at room temperature and determined by HPLC on a CAPCELL PAK C18 AG120 column (Shiseido, Tokyo, Japan) using a Waters 600 multi-solvent delivery system, Waters 486UV detector and Waters 741 data module (Millipore Corporation, Milford, MA) according to the method described by Kudou et al. (1991).

Preparation of chufa extracts

The milled chufa tubers were extracted by shaking it with 3 volumes of hexane for one hour. The mixture was centrifuged at 3000 rpm for $5 \mathrm{~min}$ and hexane layer was removed. Extraction was repeated 3 times with the solid residue and hexane layers were combined. The hexane extractable material (oil) was obtained by removing hexane under reduced pressure in a rotary evaporator and kept under argon gas at minus $30^{\circ} \mathrm{C}$ until to be used. The defatted milled tubers were stirred for $12 \mathrm{~h}$ with 7 volumes of distilled water at room temperature. The suspension was centrifuged at $3000 \mathrm{rpm}$ for 5 min and the supernatant was filtered through cotton cloth. The extraction was repeated twice and the supernatant were combined as water extract (WE). An ethanolic extract (EE) was prepared by shaking the defatted tubers powder in 5 volumes of $80 \%$ ethanol for $2 \mathrm{~h}$ at room temperature. The suspension was allowed to stand for $15 \mathrm{~min}$ and filtered through cotton cloth. Extraction was repeated twice with the solid residue and combined filtrate was centrifuged at $3000 \mathrm{rpm}$ for $5 \mathrm{~min}$. The supernatant was concentrated by removing ethanol under reduced pressure in a rotary evaporator at $40^{\circ} \mathrm{C}$. The water and ethanolic extracts were freeze-dried and solutions $(0.1 \%$ $\mathrm{w} / \mathrm{v}$ ) were prepared from the freeze-dried extracts. The $\mathrm{pH}$ values of these solutions were measured at $25{ }^{\circ} \mathrm{C}$ using pH-meter (Beckman, Instrument Company, Inc., USA). The color of the extracts was visually estimated.

\section{Preparation of liposomes}

Multil-amellar liposomes were prepared according to the method described by Yoshida et al. (1991).Briefly, egg yolk PtdCho (PC98HC, QP. Corp., Tokyo) in chloroform solution was evaporated to dryness. The dried lipid film was dispersed in $10 \mathrm{mMTris}-\mathrm{HCl}$ buffer ( $\mathrm{pH}$ 7.4) by vigorous shaking on a vortex mixer followed by ultrasonication under argon gas in ice bath for $2 \mathrm{~min}$. Final concentration in the liposomal solution was $10 \mathrm{mMPtdCho}$ and $1000 \mathrm{ppm}$ of chufa oil, WE or EE. A positive control was prepared by incorporation of $10 \mathrm{ppm}$ of Butylatedhydroxyltoluene (BHT) (NacalaiTesque Inc., Kyoto, Japan) to the liposomal solution instead of the chufa fractions. A negative control liposome sample was run simultaneously free of the investigated chufa extract or BHT.

Evaluation of antioxidant activity

The antioxidant activity of the investigated 
extracts was performed using three oxidation systems, transition metal ion-dependent peroxidation, water soluble free radical initiator and lipid soluble free radical initiator. Transition metal ion dependent peroxidation was induced by the addition of $0.1 \mathrm{mM} \mathrm{FeSO} 4,1 \mathrm{mM}$ ascorbic acid and $0.04 \mathrm{mM}$ cumen hydroperoxides $(\mathrm{CuOOH})$ (NacalaiTesque Inc., Kyoto, Japan). Free radical mediated peroxidation was induced by the addition of $20 \mathrm{mM}$ 2,2'-azobis (2-aminopropane)

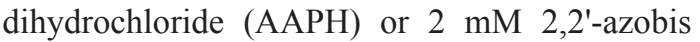
(2,4- dimethylvaleronitrile) (AMVN) (Wako Pure Chemicals Co., Osaka, Japan). AAPH and AMVN are water and lipid-soluble azo compounds that thermally decomposes and thereby generates radicals at known and constant rates (Ingold et al., 1993). Since the concentration of AMVN has to be kept low to avoid disrupting the membrane structure, the incubation temperature has to be high (i.e. $50^{\circ} \mathrm{C}$ ). The high incubation temperature may affect the antioxidant active component(s) in the extracts. For that, the liposomes were incubated at $37^{\circ} \mathrm{C}$ and accordingly the Ptd Cho-hydroperoxides increased slowly. Incubation was carried out in water bath at $37^{\circ} \mathrm{C}$ with constant shaking. The samples were removed at appropriate intervals for lipid peroxide assays. The transition metal ion dependent oxidation was terminated by adding final concentration of $20 \mu \mathrm{M}$ BHT and $2 \mathrm{mM}$ disodium ethylene diamine tetraacetic acid ( $\mathrm{Na} 2-$ EDTA). Free radical mediated peroxidation was terminated by immersing the samples in liquid nitrogen. All samples were kept at $-30^{\circ} \mathrm{C}$ until to be assayed within few hours. Lipid peroxidation was evaluated by thiobarbituric acid (TBA) assay (Jiang et al., 1992).

\section{Statistical analyses}

Statistical analysis was carried out by Duncans new multiple range test (Duncan, 1955).

\section{$\underline{\text { Results and Discussion }}$}

\section{Chemical composition of chufa tubers}

The average chemical composition of chufa tubers were as follows: $34 \%$ starch, $25 \%$ oil, $8 \%$ protein, $16 \%$ sucrose, $10 \%$ fibers and $7 \%$ others. Also, chufa tubers contained $12.38 \mu \mathrm{g} / \mathrm{g}$ and $8.46 \mu \mathrm{g} / \mathrm{g}$ of the isoflavones daidzein and genistein, respectively. Chufa tubers were extracted to three extracts using hexane, ethanol and water. The hexane fraction (oil) has a golden yellow color, pleasant odor and acceptable flavor. The fatty acid composition of the oil is shown in Table 1 . The predominant fatty acid in the oil is oleic acid (about 70\%). The oil contains also about $10 \%$ of polyunsaturated fatty acids with a small amount of $\alpha$-linoleic acid and about $20 \%$ of saturated fatty acids. The oil content of vitamin $\mathrm{E}$ is about $18.6 \mathrm{mg} / 100 \mathrm{~g}$ oil. The obtained chemical composition and fatty acid profile of chufa tubers was in consistence with that obtained by Mokady and Dolev (1970) and Oladele and Aina (2007). However, the proximate composition of chufa is quite variable and mainly dependable on their geographical origin (Codina-Torrella et al., 2015). In vitro antioxidant properties of chufa extracts

Some characteristics of the ethanolic and

TABLE 1. Fatty acid composition of chufa oil

\begin{tabular}{lc}
\hline Fatty Acid & Content (mol \%) \\
\hline Palmitic (16:0) & $13.9 \pm 0.38$ \\
Palmitoleic (16:1) & $0.38 \pm 0.01$ \\
Stearic (18:0) & $4.24 \pm 0.08$ \\
Oleic (18:1) & $71.1 \pm 0.71$ \\
Linoleic (18:2) & $9.48 \pm 0.17$ \\
Q-Linoleic (18:3,n-3) & $0.39 \pm 0.04$ \\
\hline SFA & 18.15 \\
\hline MUFA & 71.49 \\
\hline PUFA & 9.87 \\
\hline \multicolumn{2}{c}{ Data are mean \pm SE of 3 oil extracts. } \\
SFA=Saturated fatty acids. \\
MUFA=Monounsaturated fatty acids \\
UFA=Polyunsaturated fatty acids
\end{tabular}

water extracts were obtained. The yield of the ethanolic extract (EE) was $30.4 \%$ with a yellow color while the figure was $37.4 \%$ for the water extract (WE) with a light grey color. The $\mathrm{pH}$ of $0.1 \%,(\mathrm{w} / \mathrm{v})$ solution of the ethanolic and the water extracts was 4.8 and 6.2 , respectively. The effect of incorporation of $1000 \mathrm{ppm}$ of the chufa extracts to Ptd Cho liposomes on ironmediated peroxidation is shown in Fig. 1. The oil, EE and WE extracts markedly inhibited the lipid peroxide formation and resulted in significantly lower thiobarbituric acid reactive substances (TBARS) values than the control sample throughout the incubation period. The order of the antioxidant activity of the chufa extracts was WE $>$ EE $>$ oil. The addition of $10 \mathrm{ppm}$ of BHT to the liposomes completely inhibited the peroxidation progress during the incubation time. The effect of the chufa extracts in the water soluble free radical 
mediated peroxidation induced by AAPH is shown in Fig. 2. The peroxidation rate was slow as the TBARS increased slowly during the incubation time. The liposomes added with the chufa extracts significantly reduced peroxidation progress and resulted in lower TBARS than the control sample throughout the incubation period. The WE was more effective to suppress the peroxidation than the other extracts. The BHT-liposomes was more resistant to peroxidation stress and exhibited the lowest TBARS values.

Figure 3 shows the effect of incorporation the chufa extracts on the lipid soluble free radical mediated peroxidation stress induced by AMVN. Chufa oil possessed the highest antioxidantactivity as the oil added liposomes resulted in lower TBARS values than the other treatments. The peroxidation profiles of the liposomes added with the EE and WE were equivalent to that of the control samples with a slight antioxidant activity after 10 and $12 \mathrm{hr}$ of incubation. The BHT added liposomes was less susceptible to peroxidation and resulted in the lowest TBARS values.

The obtained data show that, all examined chufa fractions exhibited a marked antioxidantactivity in ferrous ions and AAPH mediated peroxidation stress, although this effect was predominant in ferrous ions dependent peroxidation. On the other hand, chufa water extract showed stronger antioxidantactivity than that of the ethanolic and hexane extracted fractions. In AMVN mediated peroxidation, liposomes added with chufa oil were less susceptible to peroxidation stress however, the other extracts did not exhibit any antioxidant activity. In our previous study (Zommara and El-Shaer 2001), chufa oil exhibited superior lipoperoxidation resistance against peroxidation stress initiated by transition metal ferrous ions, AAPH or AMVN compared to several vegetable oils and anhydrous milk fat incorporated to liposomes. Also, in an early investigation, Mohamed and El-Fors (1959) found that, the addition of $6 \%(\mathrm{v} / \mathrm{v})$ of chufa oil to linseed oil resulted in a mixture which was strongly resistant against peroxidation stress when exposed to a stream of oxygen compared to linseed oil alone. The resistance of chufa oil to peroxidation stress may be related in part, to its content of vitamin $\mathrm{E}$ and oleic acid. Lee et al.
(1998) demonstrated that, liposomes enriched in oleic acid are shown to be less susceptible to oxidation and have less pro-inflammatory activity when exposed to oxidizing condition. Also, chufa oil was found to contain remarkable concentration of essential oils (Hassanein et al., 2014). Essential oils were reported to have a powerful antioxidant capacity (Amorati et al., 2013).

The antioxidant activity of the water extract fraction (WE) may be related to tannins (Chung et al., 1998), organic acids (Niki, 1991 and Crackel et al., 1998) and water soluble proteins (Al-Saikhan, et al., 1995). In fact, Emmanuel and Edward (1984) demonstrated the presence of $0.16 \%$ of tannins in chufa tubers. The yellow color found in the ethanolic extract of chufa tubers suggests the presences of polyphenol compounds, flavonoide pigments and carotenoids (Endo et al. 1985a, b, Olson 1999) which acts as scavengers for free radicals and active oxygen (Pietta 2000, Wand et al., 2000). in this respect, our results showed that chufa tubers contains a moderate amount of the isoflavones, daidzein and genistein (12.4 and $8.5 \mu \mathrm{g} / \mathrm{g}$, respectively) which come in the ethanolic extract and may participate in the observed antioxidantactivity of this fraction. In fact, isoflavones showed antiperoxidation activity either in vitro when incorporated to liposomes (Arora et al., 1998) or in vivo when fed to experimental animals (Yousef et al., 2004).

The addition of $10 \mathrm{ppm}$ of BHT to liposomes was more effective to suppress the peroxidation stress than did $1000 \mathrm{ppm}$ of chufa tubers extracts. The BHT is a synthetic antioxidant compound and may have harmful properties to health when added to foodsatinappropriate concentration, however chufa tubers are a natural and edible plant which already used as a food ingredient in several societies without any health risk. In conclusion, chufa tubers exhibited an antioxidantactivity in in vitro peroxidation stress. Therefore, the inclusion of chufa tubers, its hexane, water or ethanol extracts in a diet may have beneficial effects on free radicals accelerated disorders such as cancer and atherosclerosis. Further studies are needed to explore this effect using laboratory animals.

\section{References}

Adejuyitan, J.A. (2011) Tigernut processing: its food uses and health benefits. Am. J. Food Tech., 6, 197201. 


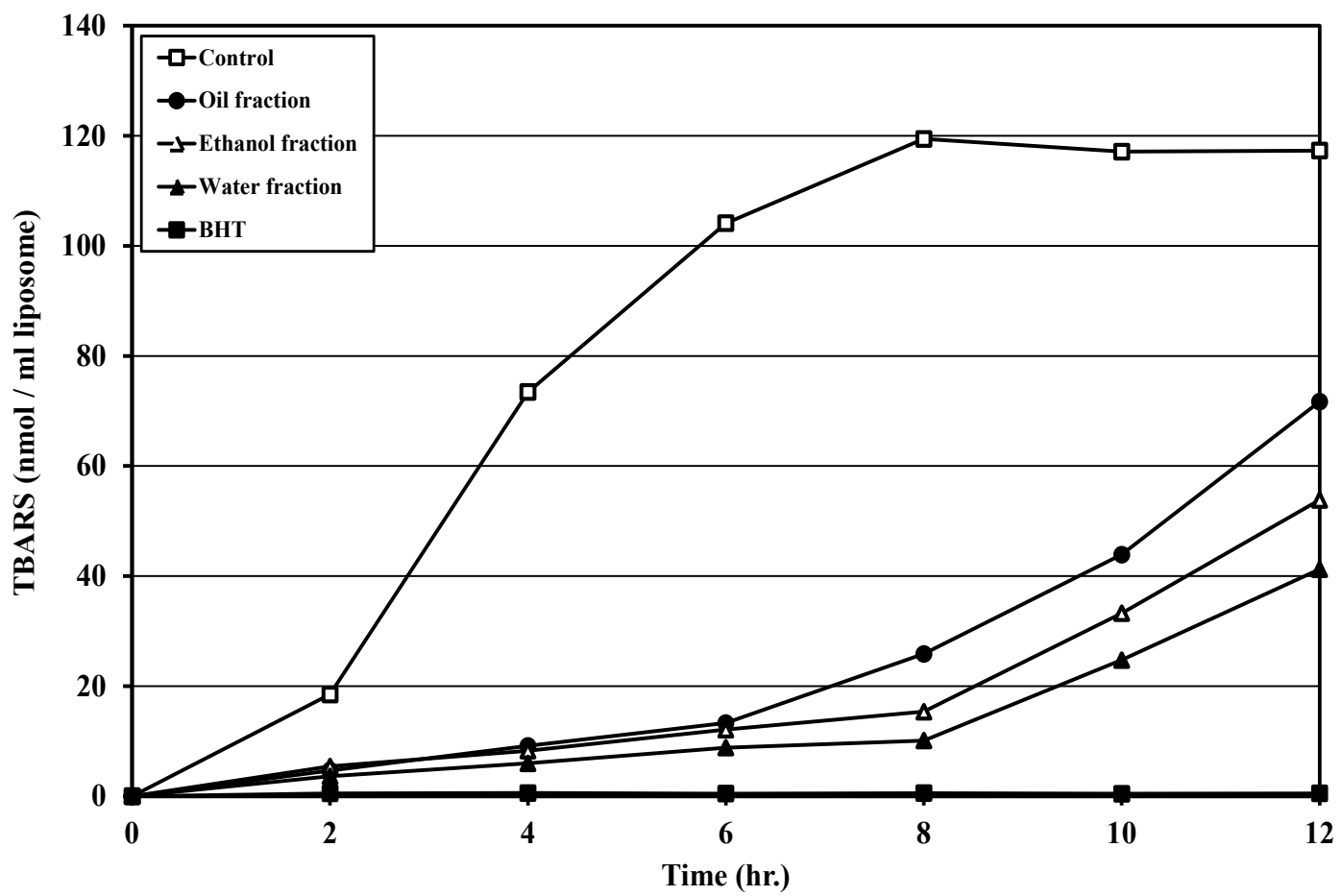

Fig. 1. In vitro ferrous ions-dependent peroxidation of PtdCho liposomes contains 1000 ppm of oil, ethanolic extract, water extract of chufa tubers or $10 \mathrm{ppm}$ of $\mathrm{BHT}$, Data are mean $\pm \mathrm{SE}$ of three replicates

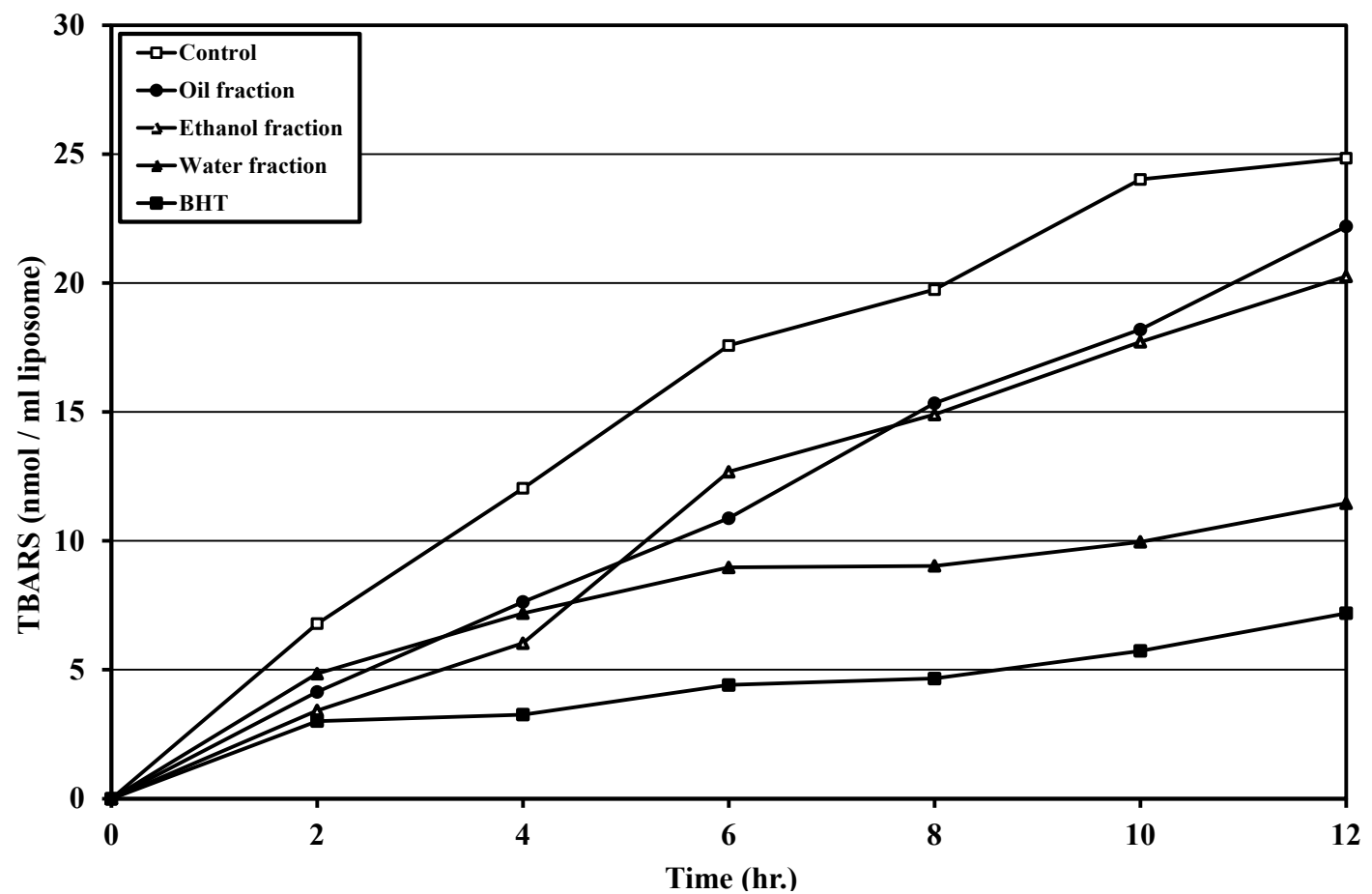

Fig. 2. In vitro AAPH peroxidation of PtdCho liposomes contains 1000 ppm of oil, ethanolic extract, water extract of chufa tubers or $10 \mathrm{ppm}$ of BHT, Data are mean $\pm \mathrm{SE}$ of three replicates 


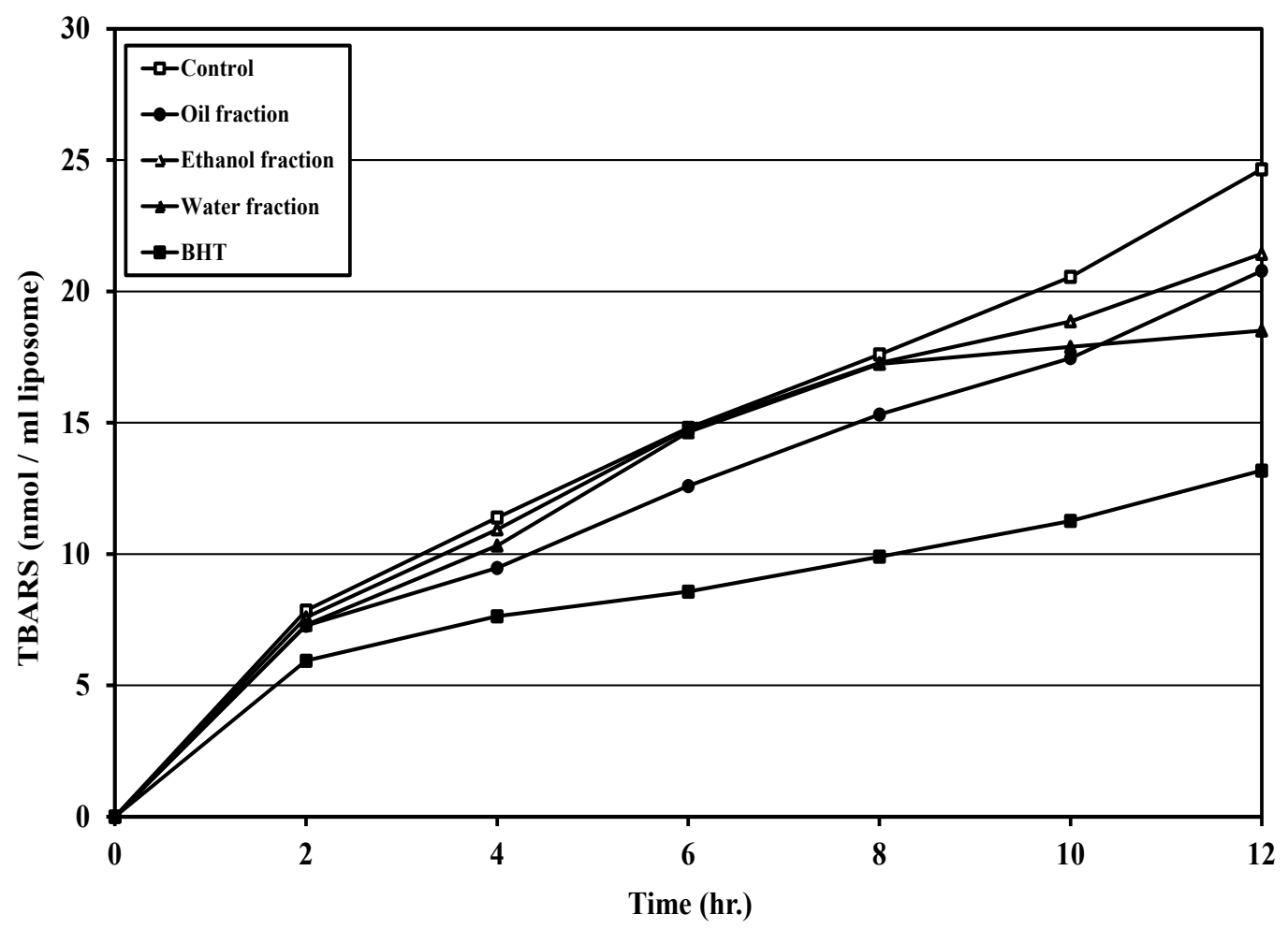

Fig. 3. In vitro AMVN peroxidation of PtdCho liposomes contains $1000 \mathrm{ppm}$ of oil, ethanolic extract, water extract of chufa tubers or $10 \mathrm{ppm}$ of BHT, Data are mean $\pm \mathrm{SE}$ of three replicates

Aguilar, N.A., lbanell, E., Minarro, B. and Capellas, M. (2015) Chickpea and tiger nut flours as alternatives to emulsifier and shortening in gluten-free bread. LWT-Food Sci. Tech., 62, 225-232.

Al-Saikhan, M.S., Howard, L.R. and Miller, J.C. (1995) Antioxidant activity and total phenolics in different genotypes of potato (Solanum tuberosum L.). J. Food Sci., 60, 341-343.

Amankwah, E.A., Barimah, A.K.M., Nuamah, J.H., Oldman, W. and Nmaji, C.O. (2009) Formulation of weaning food from fermented maize, rice, soybeans and fish meal. Pakistan J. Nutr., 8, 1747-1752.

Amorati, R. Foti, M.C. and Valgimigli, L. (2013) Antioxidant activity of essential oils. J. Agric. Food Chem., 61, 10835-10847.

A.O.A.C. (1995) "Official Methods of Analysis", $16^{\text {th }}$ ed., Washington: Association of Analytical Chemists.

Arafat, S.M., Gaafr, A.M., Basuny, A.M. and Nassef, S.L. (2009) Chufa tubers (Cyperusesculentus L): As a new source of food. World Appl. Sci. J., 7, 151-156.
Arora, A., Nair, M.G. and Strasburg, G.M. (1998) Antioxidant activities of isoflavones and their biological metabolites in a liposomal system. Arch. Biochem. Biophys., 356, 133-141.

Bamishaiye, E.I. and Bamishaiye, O.M. (2011) Tiger nut: as a plant, its derivatives and benefits. AJFAND, 11, 5157-5170.

Bonanome, A., Pagnan, A., Biffanti, S., Opportuno, A., Sorgato, F., Dorella, M., Maiorino, M. and Ursini, F. (1992) Effect of dietary monounsaturated and polyunsaturated fatty acids on the susceptibility of plasma low density lipoproteins to oxidative modification. Arterioscler. Thromb., 12, 529-533.

Cantatejo, M.J. (1997) Analysis of volatile earthalmond (Cyperus esculentus L.). J. Agric. Food Chem., 45, 1853-1860.

Chung, K.T., Wong, T.Y., Wei, C.I., Huang, Y.W. and Lin, Y. (1998) Tannins and human health. Crit. Rev. Food Sci. Nutr., 38, 421-464.

Codina-Torrella, I., Guamis, B. and Trujillo, A.J. (2015) Characterization and comparison of tiger nuts (Cyperus esculentus L.) from different geographical 
origin: Physico-chemical characteristics and protein fractionation. Ind. Crops Products, 65, 406-414.

Crackel, R.L., Gray, J.I., Bogren, A.M., Pearson, A.M. and Buckley, D.J. (1998) Effect of antioxidants on lipid stability in restructured beef meat. J. Food Sci., 53, 656-657.

Dipartimento, D. (2000) Dietary antioxidants for cardiovascular prevention. Nutri. Met. Card. Dis., 10, 38-44.

Duncan, D.B. (1955) Multi range and multiple F testes. Biometrics, 11, 1-42.

Emmanuel, O.A. and Edward, E. (1984) Nutritive value of a mixture of tigernut tubers (Cyperus esculenuts L.) and baobab seeds (Adansonia digitata L.). $J$. Sci. Food Agric., 35, 437-440.

Endo, Y., Usuki, T. and Kaneda, T. (1985a) Antioxidant effects of chlorophyll and pheophytin on the autoxidation of oils in the dark. I. Comparison of the inhibitory effects. J. Am. Oil Chem. Soc., 62, 1375-1378.

Endo, Y., Usuki, T. and Kaneda, T. (1985b) Antioxidant effects of chlorophyll and pheophytin on the autoxidation of oils in the dark. II. The mechanism of antioxidative action of chlorophyll. J. Am. Oil Chem. Soc., 62, 1387-1390.

Hassanein, H.D., Nazif. N.M., Shahat, A.A., Hammouda, F.M., Aboutable, E.A. and Saleh, M.A. (2014) Chemical diversity of essential oils from Cyperusarticulatus, Cyperusesculenuts and Cyperus papyrus. J. Essential Oil Bearing Plants, 17, 251-264.

Imaizumi, K., Abe, K., Kuroiwa, C. and Sugano, M. (1993) Fat containing stearic acid increases fecal neutral steroid excretion and catabolism of low density lipoproteins without affecting plasma cholesterol concentration in hamsters fed a cholesterol-containing diet. J. Nutr., 123, 1693702.

Ingold, K. U., Bowry, V. W., Stocker, R. and C. Walling (1993) Autoxidation of lipids and antioxidation by $\alpha$-tocopherol and ubiquinol in homogeneous solution and in aqueous dispersions of lipids: Unrecognized consequences of lipid particle size as exemplified by oxidation of human low density lipoprotein. Proc. Natl. Axad. Sci., 90, 45-49.

Jiang, Z.Y., Hunt, J.V. and Wolff, S.P. (1992) Ferrous ion oxidation in the presence of xylenol orange for detection of lipid hydroperoxide in low density lipoprotein. Anal. Biochem., 202, 384-389.

Kudou, S., Fleury, Y., Welti, D., Magnolato, D., Uchida, T., Kitamura, K. and Okubo. K. (1991) Malonyl isoflavones glycosides in soybean seeds. Agric. Biol. Chem. 55, 2227-2233.

Lee, C., Barnett, J. and Reaven, P., (1998) Liposomes enriched in oleic acid are less susceptible to oxidation and have less proinflammatory activity when exposed to oxidizing conditions. J. Lipid Res., 39, 1239-1247.

Mancini, M., Parfitt, V. J. and Rubba, P., (1995) Antioxidants in the Mediterranean diet. Can. J. Card., 11 , 105-109.

Mohamed, M.S. and El-fors, M.A. (1959) A preliminary note: chemical and technological studies on chufa tubers. Alex. J. Agric. Res., 7, 119-127.

Mokady, S.H. and Dolev, A. (1970) Nutritional evaluation of tubers of Cyperusesculenuts L. J. Sci. Fd. Agric., 21, 211-214.

Niki, E. (1991) Action of ascorbic acid as a scavenger of active and stable oxygen radicals. Am. J. Clin. Nutr., 54, 1119S-1124S.

Oladele, A.K. and Aina, J.O. (2007) Chemical composition and functional properties of flour produced from two varieties of tigernut (Cyperusesculenuts). African J. Biotech., 6, 24732476

Olson, J.A. (1999) Carotenoids and human health. Arch. Latinoameric. Nutr., 49 (3 Suppl 1), 7S-11S.

Owen, R.W., Giacosa, A., Hull, W.E., Haubner, R., Spiegelhalder, B. and Bartsch, H., (2000) The antioxidant/anticancer potential of phenolic compounds isolated from olive oil. Eur. J. Cancer., 36, 1235-1247.

Pietta, P.G. (2000) Flavonoids as antioxidants. J. Nat. Prod., 63, 1035-1042.

Sola, R., La Ville, A., Richard, L., Motta, C., Bargallo, M., Girona, J., Masana, L. and Jacotot, B., (1997) Oleic acid rich diet protects against the oxidative modification of high density lipoprotein. Free Radic. Biol. Med., 22, 1037-1045.

Wand, J.F., Scramm, D.D., Holt, R.R., Ensunsa, J.L., Fraga, C.G., Schmitz, H.H. and Keen, C.L. (2000) A dose-response effect from chocolate consumption on plasma epicatechin and oxidative damage. $J$. Nutr., 130 (8S Suppl), 2115S-2119S.

Yoshida, K., Terao, J., Suzuk,i T. and Takama, K. (1991) Inhibitory effect of phosphatidylserine on iron-

J. Sus. Agric. Sci. 43, No. 2 (2017) 
dependent lipid peroxidation. Biochem. Biophys. Res. Commun., 179, 1077-1081.

Yousef, M.I., Kamel, I.K., Esmail, A.M. and Baghdadi, H.H. (2004) Antioxidant activities and lipid lowering effects of isoflavones in male rabbits. Food Chem. Toxic., 42, 1497-1503.

Zommara, M.A. and El-Shaer, M.K. (2001) A comparative study on the resistance to in vitro lipoperoxidation of chufa oil, some vegetable oils and milk fat. Egyptian J. Dairy Sci. 29, 181-192.

Zommara, M., Toubo, H., Sakono, M. and Imaizumi, K. (1998) Prevention of peroxidative stress in rats fed on a low vitamin E-containing diet by supplementing with a fermented bovine milk whey preparation: effect of lactic acid and $\beta$-lactoglobulin on the antiperoxidative action. Biosci. Biotechnol. Biochem., 62, 710-717.

(Received 28/4/2017, accepted $20 / 7 / 2017$ ) 